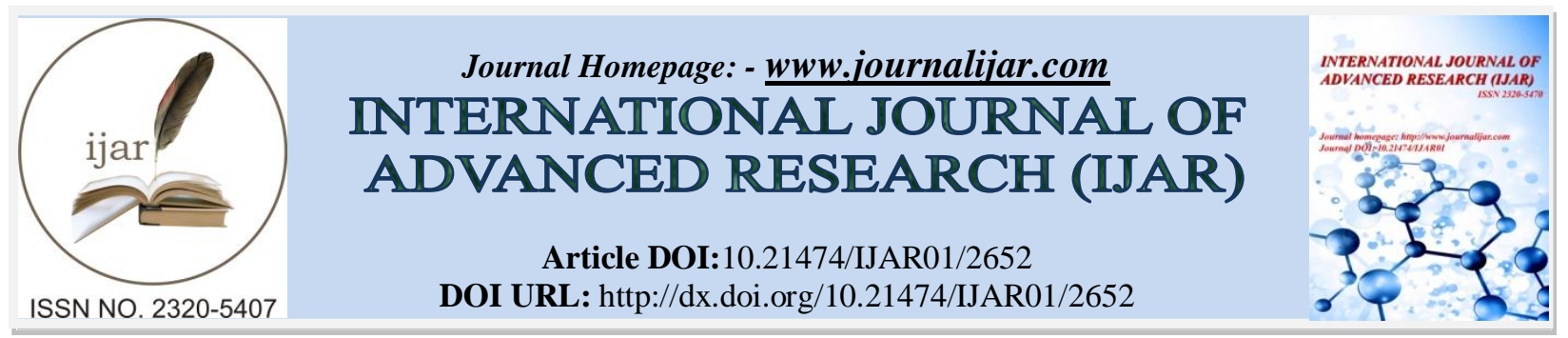

RESEARCH ARTICLE

\title{
EVALUATION OF STATIC AND DYNAMIC BALANCE IN PATIENTS WITH DIABETIC PERIPHERAL POLYNEUROPATHY: ORIGINAL RESEARCH ARTICLE.
}

Amir Abdel-Raouf El-Fiky ${ }^{1}$, Ashraf Abdelaal Mohamed Abdelaal ${ }^{* 2}$ and Omar Farouk Helal ${ }^{3}$.

1. Lecturer in Physical Therapy, Department of Physical Therapy for Neuromuscular Disorders and its Surgeries, Faculty of Physical Therapy, Cairo University, Egypt.

2. Lecturer in Physical Therapy, Department of Physical Therapy for Cardiovascular/ Respiratory Disorder \& Geriatrics, Faculty of Physical Therapy, Cairo University, Egypt.

3. Assistant Professor in Physical Therapy Department, College of Applied Medical Sciences, Umm Al Qura University, KSA.

\section{Manuscript Info}

Manuscript History

Received: 30 October 2016

Final Accepted: 29 November 2016

Published: December 2016

Key words:-

Diabetes-Polyneuropathy-Postural instability-balance.

\section{Abstract}

The Purpose of this study was to evaluate postural stability in patients with DM. Methods: Twenty-Three participants were assigned as a study group $\left(\mathrm{G}_{\mathrm{DM}} ; \mathrm{n}=23\right)$, another age-matched Twenty-Three healthy participants were assigned as a control group $\left(\mathrm{G}_{\mathrm{H}} ; \mathrm{n}=23\right)$. Evaluation procedure ran through Balance Error Scoring System (BESS), Timed Up and Go (TUG), Postural Stability Test and Limit of stability Test (LOS) on Biodex stability system. Results: revealed highly statistical significant difference in the mean values of the BESS test $(\mathrm{p}=0.003)$, the LOS test $(\mathrm{p}=0.04)$, and overall stability indexes on Biodex stability system $(\mathrm{p}=0.006)$, high significant positive correlation between BESS and the postural stability test overall scores within $\left(\mathrm{G}_{\mathrm{DM}}\right)$ (Pearson's Correlation Coefficients $(r)=0.45$ ), and high significant negative correlation between the TUG test and the LOS test overall scores within $\left(\mathrm{G}_{\mathrm{DM}}\right)(r=-0.14)$, however; the comparisons between $\left(\mathrm{G}_{\mathrm{DM}}\right)$ and $\left(\mathrm{G}_{\mathrm{H}}\right)$ showed non-statistical significant difference in the mean values of the TUG test $(\mathrm{p}=0.65)$. Conclusion: it can be concluded that diabetes affects postural stability during normal functional activity.

Copy Right, IJAR, 2016,. All rights reserved.

\section{Introduction:-}

Diabetes mellitus (DM) is a complex and complicated disease that has many complications like heart disease, stroke, hypertension, blindness, eye problems, kidney disease and nervous system disease. ${ }^{[1]}$ Approximately $60 \%$ to $70 \%$ of people with DM have mild to severe forms of nervous system affection. Nearly half patients with DM have one type or combination of motor, sensory, or autonomic neuropathy that tend to clearly appear many years after diagnosis of DM, ${ }^{[2]}$ especially in elderly patients. ${ }^{[3]}$ Diabetic peripheral neuropathy (DPN) significantly contributes to disturbed balance during daily activities through impairing feet sensation. ${ }^{[4]}$ DPN contributes significantly in falling among elderly patients. ${ }^{[5]}$ People with DPN often experience balance disorder ${ }^{[6]}$ and abnormally increased postural sway, especially with the eyes closed. ${ }^{[7]}$

Balance is the process of maintaining the center of gravity within the subject's limits of stability and influenced by the base of support. ${ }^{[8]}$ Several organs including cerebellum, skeletal muscles and the vestibular system are in

Corresponding Author:-Ashraf Abdelaal Mohamed Abdelaal.

Address:-Lecturer Physical Therapy, Department of Physical Therapy for Cardiovascular/ Respiratory 
coordinated harmony to regulate balance ${ }^{[9]}$ maintenance of standing balance and body orientation is essential for the performance of the activities of daily life and the practice of physical and sport activities. ${ }^{[7]}$

Stability can be described as the ability of dynamic system to detect and react to perturbations either external or internal muscular fluctuations. ${ }^{[10]}$ Balance is further categorized into static and dynamic subtypes, static postural control is the ability to maintain balance and undisturbed the base of support with minimal motion, while dynamic balance is the ability to perform functional task with a stable position. ${ }^{[11]}$ Maintaining adequate balance requires intact and well-integrated postural-control systems that regulate the equilibrium and orientation of the various body parts. Six physiological systems' contexts are involved in postural and balance control that include biomechanical task constraints, movement and sensory strategies, body parts orientation relative to surroundings, control of dynamics and cognitive processing. ${ }^{[12]}$ Postural instability caused by DPN increases the impact of micro-traumas and wounds. ${ }^{[13]}$ In the elderly, slips or falls are one of the most common causes of injury or death. ${ }^{[14]}$ Patients with DPNsuffer disturbed balance even with their eyes opened, and hence; increased risk for falling. ${ }^{[15]}$ Previous trials evaluating balance in patients with DPN indicated that postural instability in patients with DPN have been reflected in higher scores in postural stability indexes, ${ }^{[16]}$ speed, and area of sway; higher center of pressure (COP) ranges; ${ }^{[17]}$ higher root mean square values of the COP center of mass (COM) variable ${ }^{[18]}$ indicate lower stability control.This study was a trial to objectively explore the static and dynamic balance defects produced about by DPN.

\section{Subjects and Methods:- \\ Subjects:-}

Twenty-Three participant were assigned as a study group $\left(\mathrm{G}_{\mathrm{DM}} ; \mathrm{n}=23\right)$, another age-matched Twenty-Three healthy participant were assigned as a control group $\left(\mathrm{G}_{\mathrm{H}} ; \mathrm{n}=23\right)$. Regarding $\mathrm{G}_{\mathrm{DM}}$; they were diagnosed as having DPN, there ages ranged between 35 to 55 years with ten years or more diagnosis of diabetes. They were free of other neurological, cognition or musculoskeletal disorders that can affect the accuracy of the outcomes. They were excluded if they had balance disturbance secondary to any other disorders other than DPN (e.g. neuromuscular, musculoskeletal and vestibular), drugs that may affect balance function (i.e. minor, major tranquilizers, antihistaminic ...etc), marked visual or auditory impairments. The $\mathrm{G}_{\mathrm{H}}$ agesranged between 35 to 55 years with no sign of diabetes or other balance disturbances. Allsubjects were able tounderstand instructions directed to them during the evaluations. The study procedures followed the regional and institutional ethical standards and ran in accordance with the Helsinki Declaration of 1975, as revised in 2000. The study was conducted in the neurological rehabilitation unit, department of Physiotherapy, Umm Al-Qura University.

\section{Instrumentation:-}

The participants' data were gathered through the use of the Biodex Stability System to test postural stability and limits of stability, Balance Error Scoring System (BESS) and Timed Up and Go(TUG) test.

\section{Balance Error Scoring System (BESS):-}

The Balance Error Scoring System provides a portable, cost-effective, and objective method of assessing static postural stability;in the absence of expensive, sophisticated postural stability assessment tools.

It includes the following sex items:Double leg stance, Single leg stance, Tandem Stance, and same this three with using specific Pillow.

\section{Timed Up and Go (TUG) test:-}

It is a simple test used to assess a person's mobility and requires both good static and dynamic balance. The timed "Up and Go" test measures the time taken by an individual to stand up from a standard arm chair, walk a distance of 3 meters (118 inches, approximately 10 feet), turn, walk back to the chair and sit down. The subject wears their regular footwear and used their customary walking aid (cane or walker) and no physical assistance was given. Participants were instructed that, on the word "go"; to get up and walk at a comfortable and safe pace to a line on the floor 3 meters away, turn, return to the chair and sit down again. A stopwatch was used to record the trial time.

\section{The Biodex stability system (Biodex Corporation, Shirley, NY):-}

Biodex device was used to assess the balance ability. The system was used to test postural stability and limits of stability for all participants in the study.

The system consists of a movable balance platform, support rails and color Touch-Screen Display. A movable balance platform provided up to $20^{\circ}$ of surface tilt in a $360^{\circ}$ range, and was interfaced with a microprocessor-based actuator. The actuator controls the manually preset degree of surface instability ranging from stability level one to 
stability level 12. Support railswere two adjustable hand rails; one on each side that were used by the participant to adjust himself over the movable platform to avoid falling and to gain accurate results.Color touch-screen displayhad anadjustable display angle from vertical back up to $45^{\circ}$ and its accuracy was $\pm 1^{\circ}$ of tilt.

\section{Procedures:-}

The evaluation procedures were explained to all subjects and they were signed a consent form at the beginning of the study. Participants were initially subjected to clinical evaluation to exclude any other neurological disturbances that interfere with balance or cognition. The evaluation was started with history taking, general and medical examinations produced about by physician.

All subjects were assessed for:-

* Functional balance abilities for all participants were evaluated by using Balance Error Scoring System (BESS), In which the patient pass through six different balance activities and scored according to their errors accomplishing in the activity.

* Measuring balance abilities of the patients subjectively by using Time up and Go test.

* Evaluation of standing balance: postural stability, overall stability index and limits of stabilitywereevaluated using the Biodex Stability System.

\section{Postural stability testing procedure:-}

This test was conducted to assess the subject's ability to actively control the platform's angle of tilt. After introducing feet angles and heels coordinates into the Biodex system, the test then began. As the platform advanced to an unstable state, the subject was directed to focus on the visually feedback screen directly in front of him (while standing with both arms at the side of the body without grasping hand rails) and attempt to maintain the cursor in the middle of the bulls eye on the screen. At the end of each test a report was obtained that include information as regarding to overall stability index, medio-lateral stability index, and antro-posterior stability index which objective represents the status of one's postural stability.

\section{Overall stability index:-}

Overall stability index represents the subject's ability to control his balance in all directions. High records show that the subject had difficulty. The mean values of three trials, of stability index on both stability levels (level ten) were calculated for each subject individually.

\section{Limits of stability (LOS ) testing procedure:-}

The subjects carried out the dynamic limits of stability protocol, consisting of moving the cursor (platform) back and forth from a central box to eight peripheral boxeson the screen. The performance is based on their ability to accurately move the display cursor to a target 10 degrees from a level platform position and back to level again. The subject was instructed to start moving the cursor toward the flashing target. The cursor had to stay within the center point for a minimum of 0.5 seconds before it disappeared and showed the next target on the screen. Each trial ended when the eight target points had been reached and cursor was return to the center point.

The dynamic LOS score was calculated for each direction according to the percentage between the straight line distance to target and the number of samples.

\section{Statistical Analysis:-}

Statistical analyses were performed using GRAPHPAD (version 3.05) to compare the main differences between the two groups. Data were presented as mean \pm SD. For comparison between the two groups regarding the scores of Timed Up and Go test, Balance Error Scoring and postural stability test mean scores; the unpaired T-test was used.Pearson's correlation coefficient ( $\mathrm{r}$ ) was used to correlate between MMSE and postural stability mean scores. Values of (r) ranged from 0 (no correlation), 0-0.2 (very low and probably meaningless), 0.2-0.4 (a low correlation that might warrant further investigation), 0.4-0.6 (a reasonable correlation), 0.6-0.8 (a high correlation) and 0.8-1 (a very high correlation. The level of significance was set at $\mathrm{p}<0.05$ (when $\mathrm{P}=0.05$ is classed as "significant", $\mathrm{P}=$ 0.01 as "highly significant" and $\mathrm{P}=0.001$ as "Extremely significant"). 


\section{Results:-}

Twenty-Three male patients with DPN compared to the same number of healthyindividuals participated in this study. The DPN group represents the study group $\left(\mathrm{G}_{\mathrm{DM}}\right)$ and the healthy group represents the control group $\left(\mathrm{G}_{\mathrm{H}}\right)$.

Both groups were matched as closely as possible in term of age, body weight and height. There were non-significant differences in demographic characteristics between both groups, P> 0.05 (table 1). Participants in eithergroup were evaluated using Timed Up and Go test, the Balance Error Scoring System, the postural stability test and the Limit of stability test. The last two tests were parts of the Biodex stability system device.

Table I:-General characteristics of participants in both groups (mean $\pm \mathrm{SD}$ ).

\begin{tabular}{|c|c|c|c|c|}
\hline \multirow{2}{*}{ Character } & $\mathbf{G}_{\mathbf{D M}}$ & $\mathbf{G}_{\mathbf{H}}$ & \multirow{2}{*}{ t-value } & \multirow{2}{*}{ p-value } \\
\cline { 2 - 3 } & $\mathbf{X} \pm \mathbf{S D}$ & $\mathbf{X} \pm \mathbf{S D}$ & & $0.19^{* *}$ \\
\hline Age (yr.) & $44 \pm 11$ & $39 \pm 13$ & 1.3 & $0.59^{* *}$ \\
\hline Height (cm.) & $170 \pm 8.5$ & $170 \pm 9.4$ & 0.54 & $0.11^{* *}$ \\
\hline Weight (kg.) & $89 \pm 19$ & $80 \pm 19$ & 1.6 & \\
\hline
\end{tabular}

$\mathbf{G}_{\mathrm{DM}}$ : Diabetic peripheral neuropathy "study" group; $\mathbf{G}_{\mathrm{H}}$ : Healthy "control" group; $\mathbf{X}:$ mean; SD: standard deviation; yr.: years; cm: centimeter; Kg.: kilogram; **: Non-significant $(\mathrm{P}>0.05)$.

Table II:- Between-groups comparison of mean values of Times Up and Go test (TUG), Balance Error Scoring System (BESS), postural stability test mean scores and the limit of stability test (LOS).

\begin{tabular}{|c|c|c|c|c|c|}
\hline & $\mathbf{G}_{\mathbf{D M}}$ & $\mathbf{G}_{\mathbf{H}}$ & T-value & P-value \\
\hline \multicolumn{2}{|c|}{ TUG } & $9.1 \pm 1.6$ & $8.9 \pm 1.8$ & 0.45 & $0.65^{* *}$ \\
\hline \multicolumn{2}{|c|}{ BESS } & $26.9 \pm 9.7$ & $18 \pm 9.3$ & 3.18 & $0.003^{*}$ \\
\hline \multirow{2}{*}{$\begin{array}{c}\text { The postural } \\
\text { stability test }\end{array}$} & $\mathbf{M} / \mathbf{L}$ & $1.1 \pm 0.66$ & $0.93 \pm 0.94$ & 0.72 & $0.47^{* *}$ \\
\cline { 2 - 6 } & $\mathbf{A} / \mathbf{P}$ & $1.76 \pm 0.82$ & $1.09 \pm 0.65$ & 3.07 & $0.004^{* *}$ \\
\cline { 2 - 6 } & Overall & $2 \pm 1.08$ & $1.2 \pm 0.77$ & 2.9 & $0.006^{*}$ \\
\hline \multicolumn{2}{|c|}{ LOS } & $19.57 \pm 8.4$ & $14.7 \pm 6.8$ & 2.16 & $0.04^{*}$ \\
\hline
\end{tabular}

$\mathbf{G}_{\mathrm{DM}}$ : Diabetic peripheral neuropathy group; $\mathbf{G}_{\mathrm{H}}$ : Healthy group; X: mean; SD: standard deviation; TUG: Timed Up and Go test; BESS: Balance Error Scoring; System; M/L: Medio-lateral; A/P: Antro-posterior; LOS: Limit of Stability; **: Non-significant $(\mathrm{P}>0.05) ; *$ : Significant $(\mathrm{P}<0.05) ;{ }^{*}$ : Highly significant $(\mathrm{P} \leq 0.01)$.

Between-groups comparison revealed that there non-significant differences in mean values of Timed Up and Go test $(\mathrm{P}=0.65)$, Medio-lateral postural stability test $(\mathrm{P}=47)$, while there were significant differences in mean values of Balance Error Scoring System (BESS) $(\mathrm{P}=0.003)$, Antro-posterior postural stability test $(\mathrm{P}=0.004)$, overall postural stability test $(\mathrm{P}=0.006)$ and Limits of Stability test $(\mathrm{P}=0.04) .($ table 2$)$.

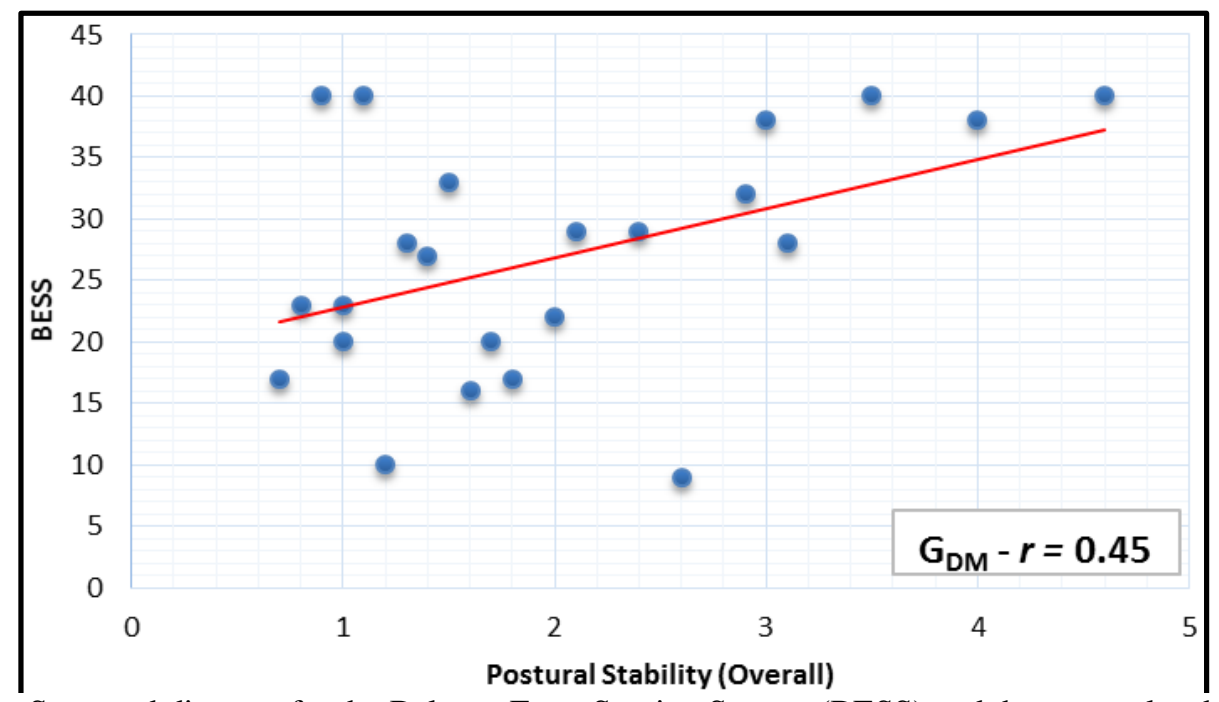

Figure 1:- Scattered diagram for the Balance Error Scoring System (BESS) and the postural stability test overall scores within the study " $\mathrm{G}_{\mathrm{DM}}$ " group. 
Results also revealed that there was significant reasonable correlation between the Balance Error Scoring System and the postural stability test overall scores $(\mathrm{r}=0.45, \mathrm{P}=0.03)$ (figure.1), while there was non-significant (a very low correlation) correlation between the Timed Up and Go test and the limit of stability test overall scores within the study " $\mathrm{G}_{\mathrm{DM}}$ " group $(\mathrm{r}=-0.14, \mathrm{P}=0.53)$ (figure. 2 ).

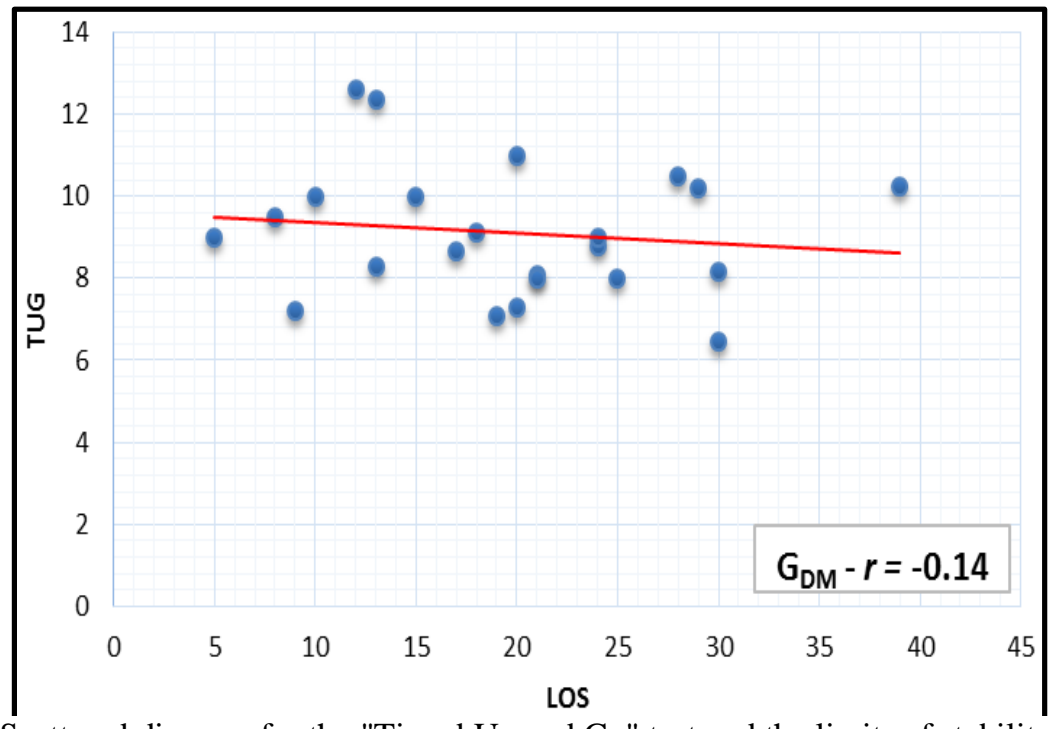

Figure 2:- Scattered diagram for the "Timed Up and Go" test and the limits of stability test overall scores within the study " $\mathrm{G}_{\mathrm{DM}}$ " group.

\section{Discussion:-}

People with DPN often experience balance disorder, ${ }^{[6]}$ as well as increased postural sway. ${ }^{[7]}$ Patients with DPN suffer impaired feet sensation and reduced ability to control balance during functional activities. ${ }^{[4]}$ Disturbed balance in patients with DPN is attributed to impaired proprioception, ${ }^{[19]}$ deteriorated movements strategies as well as biomechanical and structural disorientation. ${ }^{[20]}$

The aim of the present work was to determine the influence of diabetes mellitus on static and dynamic balance, in addition to investigate the validity of using the Balance Error Scoring System (BESS) test as a tool in evaluating static balance as well as to investigate the validity of using the Timed-Up and Go test (TUG) as a tool in assessing dynamic balance. The results revealed significant differences between the two group in mean values of Biodex balance test and BESS, while there was non-significant difference between groups in mean TUG values. Results of current study revealed that diabetes has deteriorus effect on balance and postural stability. These alternations can be attributed to the existence of serious sagittal, coronal and transverse biomechanical deteriorations significantly aggravated by macro- and microangiopathies in the weight- bearing structures that are involved in both postural balance and gait. These pathological changes are detectable in diabetic patients even in the absence of DPN. ${ }^{[21]}$ Diabetesitself harms vestibular function, large segment of patients with diabetes develop vestibular dysfunction even before feet sensory impairment that in turn impair functional balance. ${ }^{[22]}$

Regarding the harmful impact of DPN on balance; the current study results were supported by previously published reports that stated that patients with DPN are at increased risk of fall that is mainly attributed to the DPN-related balance problems ${ }^{[23]}$ Furthermore; Lafond et al., 2004 reported that DPN aggravates the functional instability ${ }^{[10]}$ and predispose to poor postural control during daily activities which is considered among major contributor and major intrinsic factor to fall ${ }^{[2]}$ This increased risk of loss of functional balance among patients with DPN may be due to the direct effect of DPN on neuromuscular system or the compensatory strategies the body adopt due to lack of somatosensory inputs. ${ }^{[25]}$

Comparisons between the two groups showed a very highly significant difference in the mean values of the overall scores of the postural stability and limits of stability tests(Biodex balance tests).These findings are supported by Arnold et al.,1998 ${ }^{[26]}$ who reported that theBiodex balance system provides information more specifically on ankle joint movements. The postural stability test score calculates overall stability index (OSI) from the degrees of tilt 
about the antro-posterior (AP) and medio-lateral (ML) axes and separately calculates ML stability index (MLSI) and AP stability index (APSI), with a high score in the indexes indicates poor balance.

Comparisons between the two groups showed no statistical significant difference in the mean values of the timed- up and go (TUG) test. These findings are supported by Samson et al., 2000 ${ }^{[27]}$ who reported that TUG test did not give sufficient information to guide the choice of intervention, even though it can be useful in assessing the effect of such treatment. Therefore, a test that includes the same subtasks as the TUG, but that scores each subtask separately, can possibly add information of relevance for clinical decision making in rehabilitation and geriatric medicine and in evaluating changes over time. Current results revealed that diabetes adversely impact balance and postural stability, these findings were supported by Fay et al., 2002 $2^{[28]}$ who reported that compared with age-matched control subjects; subjects with DPN had significant reduction in proprioception and cutaneous sensation at the feet, allowing for more postural sway in patients with DPN compared with normal healthy subjects during stance on a stable surface, both with eyes open and eyes closed.

The DPN patients showed a less stable posture, larger ranges of sway and elevated incidence of injury during walking or standing than that of control subjects with and without vision, the situation that allow to accept the hypothesis that central deficits rather than peripheral deficits caused the less stable posture observed for the patients with DPN. Balance evaluation among patients with DPN should receive adequate attention, particularly in elderly or severely affected patients ${ }^{[4]}$ because patients with DPN usually tend to relay on vestibular sensory inputs for orientation and ignore somatosensory inputs because supporting surface is usually interrupted as unstable. ${ }^{[29]}$ Additionally; Patients with T2DM even without DPN tend to have less than normal motor behavior and reduced physical function especially in elderly individuals. ${ }^{[30]}$ Conclusion:Diabetes mellitus adversely impacts postural stability during functional activities. The deteriorus effects clearly appear during both static and dynamic situations. The magnitude of functional alternation can be objectively evaluated and compared with matched normal healthy controls.

\section{Acknowledgment:-}

The authors would like to express their appreciation to all patients for their participation and cooperation in this study.

\section{References:-}

1. American Diabetes Association. Diagnosis and Classification of Diabetes Mellitus.(Position statement).Diabetes Care 2005; 28: S37-S42.

2. Hilton TN, Tuttle LJ, Bohnert KL, Mueller MJ, Sinacore DR. Excessive Adipose Tissue Infiltration in Skeletal Muscle in Individuals With Obesity, Diabetes Mellitus, and Peripheral Neuropathy: Association With Performance and Function. Physical Therapy 2008; 88 (11): 1336- 1345.

3. Corriveau H, Prince F, Hébert R, Raîche M, Tessier D, Maheux P, Ardilouze JL. Evaluation of postural stability in elderly with diabetic neuropathy. Diabetes Care 2000; 23(8):1187-91.

4. Boucher P, Teasdale N, Courtemanche R, Brad C, Fleury M. Postural stability in diabetic polyneuropathy. Diabetes Care 1995; 18: 638-45.

5. Maurer MS, Burcham J, Cheng H. Diabetes mellitus is associated with an increased risk of falls in elderly residents of a long-term care facility. J Gerontol A BiolSci Med Sci 2005; 60(9):1157-62.

6. Uccioli L, Giacomini PG, Monticone G, Magrini A, Durola L, Bruno E, Parisi L, Di Girolamo S, Menzinger G. Body sway in diabetic neuropathy. Diabetes Care 1995; 18(3): 339-344.

7. Ahmmed AU, Mackenzie IJ. Posture changes in diabetes mellitus. J Laryngol Otol. 2003;117(5):358-64.

8. Yim-Chiplis PK, Talbot LA. Defining and measuring balance in adults. Biological Research for Nursing 2000; 1(4): 321-331.

9. Matsumura BA, Ambrose AF. Balance in the elderly. ClinGeriatr Med 2006; 22: 395-41.

10. Lafond D, Corriveau H, Prince F. Postural control mechanisms during quit standing in patients with diabetic sensory neuropathy. Diabetes Care 2004; 27:173-8.

11. Winter DA. A.B.C. (Anatomy, Biomechanics and Control) of balance during standing and walking. Waterloo: Waterloo Biomechanics; 1995.

12. Macpherson JM, Fung J, Jacobs R. Postural orientation, equilibrium, and the spinal cord. Adv Neurol. 1997; 72: 227-32. 
13. Horak FB. Postural orientation and equilibrium: What do we need to know about neural control of balance to prevent falls? Age Aging 2006; 3 (Suppl 2): ii7-ii11.

14. Katoulis EC, Ebdon-Parry M, Hollis S, Harrison AJ, Vileikyte L, Kulkarni J, Boulton AJ. Postural instability in diabetic neuropathic patients at risk of foot ulceration. Diabet Med 1997; 14(4):296-300.

15. Kim BJ, Robinson CJ. Effects of diabetic neuropathy on body sway and slip perturbation detection in older population. Int J OccupSafErgon 2006; 12(3):241-54.

16. Speers RA, Kuo AD, Horak FB. Contributions of altered sensation and feedback responses to changes in coordination of postural control due to aging. Gait Posture 2002; 16(1):20-30.

17. Aly FA, Fawzy E, Ibrahim M, Mohamed A. Assessment of stability deficits in patients with Diabetic peripheral neuropathy. Bull Cairo UnivFac 2007; 12(1):31-42.

18. Yamamoto R, Kinoshita T, Momoki T, Arai T, Okamura A, Hirao K, Sekihara H. Postural sway and diabetic peripheral neuropathy. Diabetes Res ClinPract 2001; 52(3):213-21.

19. Akbari M, Karimi H, Farahini H, Faghihzadeh S. Balance problems after unilateral lateral ankle sprains. J Rehabil Res Dev 2006; 43(7):819-24.

20. De Oliveira CB, De Medeiros IR, Frota NA, Greters ME, Conforto AB. Balance control in hemiparetic stroke patients: main tools for evaluation. J Rehabil Res Dev 2008; 45(8):1215-26.

21. Greenman RL, Khaodhiar L, Lima C, Dinh T, Giurini JM, Veves A. Foot small muscle atrophy is present before the detection of clinical neuropathy. Diabetes Care 2005; 28(6):1425-30.

22. Petrofsky J, Morris A, Jorritsma R, Bonacci J, Bonilla T. Aerobic Training On A Portable Abdominal Machine. J Appl Res ClinExpTher 2003; 3:402-415.

23. Said G. Diabetic neuropathy-A review. Nat ClinPractNeurol 2007; 3(6):331-40.

24. Cordeiro RC, Jardim JR, Perracini MR, Ramos LR. Factors associated with functional balance and mobility among elderly diabetic outpatients. Arq Bras EndocrinolMetabol 2009; 53(7):834-43

25. Nardone A, Grasso M, Schieppati M. Balance control in peripheral neuropathy: are patients equally unstable under static and dynamic conditions? Gait Posture 2006; 23: 364-373.

26. Arnold BL, Schmitz RJ. Examination of balance measures produced by the Biodex stability system. J Athl Train. 1998; 33(4):323-27.

27. Samson MM, Meeuwsen IBAE, Crowe A, Dessens JAG, Duursma SA, Verhaar HJJ. Relationships between physical performance measures, age, height and body weight in healthy adults. Age and Ageing 2000; 29: 235242.

28. Fay B. Horak, Ruth Dickstein, Robert J. Peterka, Diabetic neuropathy and surface sway-referencing disrupt somatosensory information for postural stability in stance. Somatosens Mot Res 2002; 19(4): 316-326.

29. Mergner T, Nasios G, Anastasopoulos D. Vestibular memory-contingent saccades involve somatosensory input from the body support. Neuroreport 1998; 11;9(7): 1469-73.

30. Demirbüken I, İlçin N, Gürpınar B, Algun C. The Effect of Type 2 Diabetes Mellitus on the Motor Behaviour of Elderly Individuals During Sit to Stand Activity. Journal of Marmara University Institute of Health Sciences 2012; 2(2): 72-77. 